\title{
Effects of low intensity interval training on physiological variables of university students
}

\author{
Assegid Ketema ${ }^{\mathrm{ABCDE}}$ \\ Arba Minch University, Ethiopia
}

Authors' Contribution: A - Study design; B - Data collection; C - Statistical analysis; D - Manuscript Preparation; E - Funds Collection

\begin{abstract}
Background This study was to investigate the effects of low-intensity interval training on the physiological variables of and Study Aim university students.

Material and Forty male sports science students aged 18-25 years were randomly assigned to the Experimental group Methods $\quad(n=20)$ and the Control group $(n=20)$. The Experimental group underwent low-intensity interval training for eight weeks, whereas the Control group did not. Measurements of physiological variables such as resting heart rate, respiratory rate, recovery heart rate, breath-hold time, maximal oxygen uptake, and blood pressure were obtained for all subjects before and after the intervention. To compare the mean physiological variables between the experimental and control groups, an independent samples t-test was used.

Results Statistical significance was set at $\mathrm{p}$ 0.05. After the training intervention, the experimental group showed significantly better improvements than the control group in resting heart rate, respiratory rate, recovery heart rate, breath-holding time, maximal oxygen uptake, and blood pressure ( $p$ 0.05). Post intervention maximum oxygen uptake was statistically significant with $t(38)=3.086, p$ value 0.004 . Post experiment systolic blood pressure was statistically significant with $t(38)=-2.405, p$ value 0.021 for low intensity interval training and control group. Post experiment diastolic blood pressure was statistically highly significant with $\mathrm{t}(38)=0.569$, p value 0.001 for low intensity interval training and control group. The result of the study showed that there was a significant difference in post rest heart rate, respiratory rate, recovery heart rate, systolic blood pressure, diastolic blood pressure, breath holding and maximal oxygen uptake between the low intensity interval training and the control group ( $p 0.05)$.

Conclusions: Thus, it was concluded that eight weeks of low-intensity interval training show significant improvement in physiological variables of university students.

Keywords: $\quad$ blood pressure, breathe holding time, maximal oxygen uptake, resting heart rate, recovery rate.
\end{abstract}

\section{Introduction}

Interval training refers to the basic concept of alternating periods of relatively intense exercise with periods of lower-intensity or complete rest for recovery. Low-volume interval training refers to sessions that involve a relatively small amount of exercise [1]. Lowintensity interval training (LIIT) is the minimum exercise intensity threshold for improving aerobic capacity at a minimum 40 - 45\% maximal oxygen uptake (Vo2max) [25]. Low-intensity resistance exercise provides successful results when performed with circulatory occlusion, even for a short duration of training [6].

Low-volume high-intensity interval training seems to be an efficient and practical way to develop physical fitness [7]. Low-intensity training consisted of treadmill running 3 days/week, $55 \mathrm{~min} /$ day, for 15 weeks, beginning and started 2 months post banding ( $\approx 10$ months old) with gradually increasing intensity, as tolerated, until finally consisting of: 1) 5-min warm-up at $2 \mathrm{mph}$; 2) six 5-min sessions at $3 \mathrm{mph}$ with five 3 -min intervals at $4 \mathrm{mph}$ in between; and 3) 5-min cool down at $2 \mathrm{mph}$ [8-10].

Low-intensity interval training preserved normal coronary vascular function and smooth muscle cell $\mathrm{Ca} 2$-sensitive $\mathrm{IK}+$, illustrating a potential mechanism

(c) Assegid Ketema, 2021

doi:10.15561/26649837.2021.0508 underlying coronary vascular dysfunction in a largeanimal model of Left ventricular(LV) hypertrophy. Lowintensity interval training attenuated increased fibrosis, collagen deposition, and mitochondrial dysfunction. Lowintensity interval training preserved normal coronary vascular function in vivo and maintained coronary smooth muscle cell $\mathrm{Ca} 2$-sensitive IK in miniature swine with LV hypertrophy [8].

The low-intensity exercise-induced decreases of resting heart rate (RHR) was positively related with the pre-interventional RHR and negatively with the average age of the participants. The exercise-especially endurance training and yoga-decreases RHR. This effect may contribute to a reduction in all-cause mortality due to regular exercise or sports [11]. The aerobic fitness was associated with RHR in both sexes, indicating that lower aerobic fitness values were associated with higher RHR values [12].

Low-intensity exercise training applied during chronic Doxorubicin treatment protects against cardiac dysfunction following treatment, possibly by enhancing antioxidant defenses and inhibiting apoptosis [13]. Lowintensity norm duration training significantly improved peak aerobic and sprint power output, efficiency and physical strain in able-bodied untrained individuals. Training at 30\% recovery heart rate (HRR) (3-6/week, 30 
min/session) may be appropriate in untrained individuals, such as novice wheelchair users at the start of their rehabilitation, to prevent early fatigue and overuse and enhance motivation [14].

Data suggest that high-intensity interval training was equally effective as endurance training in decreasing mean arterial pressure, Systolic blood pressure (SBP), diastolic blood pressure (DBP), and circulating $\mathrm{C}$-reactive protein. High-intensity interval training was equally as effective as endurance training in improving $\mathrm{VO} 2$ max. Importantly, these effects seen with high-intensity interval training occurred with substantially less total exercise time and volume than endurance training [15-17].

Low volume high-intensity interval exercise can considerably improve aerobic fitness, body composition, and cardio metabolic health in a variety of populations [1820]. Low-intensity exercise training significantly delays the onset of heart failure and improves survival in female hypertensive heart failure rats without eliciting sustained improvements in blood pressure, cardiac function, or expression of several myocardial proteins associated with the cardiovascular benefits of exercise [21]. Chronic lowintensity interval training attenuates diastolic impairment by promoting compliant extracellular matrix fibrotic components and pre- serving extracellular matrix regulatory mechanisms preserve myocardial oxygen balance and promote a physiological molecular hypertrophic signalling the phenotype in a large animal model resembling heart failure with preserved ejection fraction [10].

Daily physical activity level was correlated with systolic blood pressure during resistance exercise at $20 \%$ and $40 \% 1 \mathrm{RM}$, and that systolic blood pressure during resistance exercise decreased after 6 wks of aerobic exercise training. These results suggest that habitual exercise decreases systolic blood pressure during lowintensity resistance exercise [22].

Children and adolescents are recommended to undertake at least $60 \mathrm{~min}$ of daily moderate to vigorous exercise [23]. However, studies with objective assessment of physical activity show a significant decline in physical activity in childhood and adolescence [24] and that few children and adolescents meet the recommended daily dose of physical activity $[25,26]$. The goals of physical training are to increase the physiological potential of the athlete and to develop bio-motor skills at the highest level [27]. University students represent the future of families, communities, and countries. They are exposed to pressures as they try to achieve their academic goals and are likely to become future leaders in their society, whether in business, education, or politics. It has been argued that health is an important factor in academic success in school and higher education.

According to the above results on low-intensity interval training has a positive effect on physiological variables. The result of this study may be important to physical education teachers, fitness instructors, and coaches who should incorporate a variety of low-intensity interval training methods for physiological variables to improve the physical fitness level of their trainees.

\section{Materials and Methods}

\section{Participants}

There are currently 103 male sports science students in the study area. Out of them 40 sample students were selected using simple random sampling technique.

To achieve the purpose of the study, the untrained male sports science students were selected from those who were not in any playing or sports team or training program and also free from deformities and ailments. They were randomly divided into two groups, lowintensity interval training (LIIT) group $(n=20)$ and control (C) group $(n=20)$. The experimental (E) group was trained with LIIT and the control group received no training.

A true experimental design was used in this study. According to Guetterman et al., and Bryman, such design helps to generalize and predict from a sample population so that inferences can be made about the outcome of the study population [28, 29].

Therefore, the present study was conducted to investigate the effect of low-intensity interval training on selected physiological variables of Dilla University male sport science students.

The requirements of the project were explained to all subjects and all voluntarily agreed to undergo the testing and training program. A thorough orientation on the requirements of the experimental testing procedure as well as the exercise protocol was well explained to all participants to calm uneasiness and written informed consent was obtained from them.

\section{Research Design}

Blood pressure was recorded while students in are in a comfortable sitting position with the right arm fully exposed and resting on a supportive surface at the heart level; a mercury sphygmomanometer was used with an appropriately sized cuff. At the same time, three resting heart rate measurements (radial pulse) were taken after 5, 10 , and 15 minutes of being in a sitting position, and the mean was calculated. Resting heart rate was recorded by a physician over a 1-min period [30].

Wash hands with soap and water to Gain the students in a comfortable position. Maintain a constant temperature remove bulky clothing and observing depth, symmetry, and pattern of breathing. If the students are sitting, their feet must be flat on the floor. Allow the students to rest, if possible, for 20 minutes before taking the measurement. When measuring respiratory rate the students were blinded to the specific aims of the study and the simulated students not specifically advised when the respiratory rate was being measured. Using a stopwatch with a second hand, count breaths (number of times the chest moves up and down) for a full minute. This length of time is needed as changes can occur in the respiratory pattern and rate. Record the respiratory rate on the recording paper [31, 32].

To measure breath-holding time primarily fill the plastic bag. With a nose clip in place, have the students take a large breath of room air and then exhale into a previously empty plastic bag, closing the bag so that it stays full. Once the bag is full of expired air, have the 
students resume normal breathing in and out of the closed bag. Have the time recorder start the stopwatch when the participant begins to rebreathe. The participant should continue to rebreathe until their depth of breathing causes the bag to collapse or until the students reach their limit of tolerance. The observer should terminate the test if the participant exhibits any signs or symptoms of discomfort or dizziness. In our experience, rebreathing should be limited to no longer than $2 \mathrm{~min}$. The duration of rebreathing should be recorded in the data collection sheet, along with any observations of changes in rate and depth of breathing [33, 34].

Students consumed a light breakfast 2-3 hours before the test and refrained from any vigorous physical activity during this period. The students had no history of serious diseases and did not perform any physical conditioning program except for some recreational sports. The maximal oxygen uptake of each subject was determined by indirect methods. Subjects were asked to rest for at least half an hour before exercise. Subjects ran on a 400 -meter track for a total duration of $12 \mathrm{~min}$. They were highly motivated to run as many laps as possible. The total number of laps was counted and the finish point was marked. The total distance (in meters) covered in $12 \mathrm{~min}$ was calculated by multiplying the number of complete laps by 400 plus the distance (in meters) covered in the last incomplete lap. The distance in meters was converted to $\mathrm{km}$ and the following equation was used to predict VO2max.

$$
\begin{aligned}
\mathrm{VO}_{2} \max \left(\mathrm{ml} \cdot \mathrm{kg}^{-1} \cdot \mathrm{min}^{-1}\right) & =(22.351 \times \text { distance covered in } \\
\mathrm{kilometres}) & -11.288[34,35] .
\end{aligned}
$$

Heart rate was measured in a supine, standing, during each minute of exercise, at maximum exercise, and in recovery at $1,2,3$, and $5 \mathrm{~min}$. Heart rate recovery was defined as (maximum heart rate - heart rate at a specified time period after exercise) and represented the drop in heart rate during that time interval $[36,37]$.

Statistical Analysis-

The data collected on the selected physiological variables in pre and post-test were analyzed, interpreted, and tabulated into a meaningful way by using IBM-SPSS version 20 (IBM, Armonk, NY, United States of America) and analysis of independent sample t-test was used. Mean difference and standard deviation was used in order to compare components of the variable levels among the experimental and control groups. For the study, the significance level for all data was $\mathrm{p}<0.05$.

\section{Results}

The demographic characteristics of the participants were explained in Table 1. The mean age, body mass, height and body mass index of the experimental groups were 21.15 years, $62.93 \mathrm{~kg}, 1.69 \mathrm{~m}$ and 22.34 respectively, while the control groups were 20.95 years, $62.45 \mathrm{~kg}, 1.69$ $\mathrm{m}$ and $21.81 \mathrm{~m}$ tall respectively. Thus, the groups were well matched at entry. Various research findings suggest that body mass index is a useful tool to study the general population to determine health risks and recommended body mass. The acceptable body mass index for the general population ranges from 18.5 to $24.99 \mathrm{~kg} / \mathrm{m} 2$ appearance her

After the Intervention between Group Comparisons

After eight weeks of the intervention, the effects of the mean physiological variables are described in Table 2. The result of the study shows that the mean of resting heart rate, respiratory rate, recovery rate, breath holding, Vo2max, systolic blood pressure and diastolic blood pressure had positive effects on both health and performance.

The mean RHR for LIIT was $63 \pm 6.88$, while it was $74.1 \pm 7.09$ in the control group. The respiratory rate was $\mathrm{M}=17.65$ for LIIT while it was $\mathrm{M}=21.90$ for the control group. The recovery rate for LIIT was $\mathrm{M}=17.70$, while for control group $\mathrm{M}=38.50$. The LIIT after intervention for breath holding was $\mathrm{M}=45.41$, while for control group 33.13. After exercise, the Vo2max for LIIT was $M=47.44$, while for control group $M=39.64$. The LIIT for systolic blood pressure and diastolic blood pressure was $M=114$, 69, while for control group 120.5 and 78, respectively.

Results of between-group comparisons were explained in table 3. The result of the study showed that there was a significant difference in post-resting heart rate, respiratory rate (RR), recovery heart rate, systolic, diastolic blood pressure, breath-hold (BHT), vo2-max between LIIT and Control group $(\mathrm{p}<0.05)$.

Low-intensity interval training and control group of students resting heart rate has a statistically significant difference with $\mathrm{t}(38)=-5.023, \mathrm{p}$-value $<0.001$. This indicates that LIIT had a lower resting heart rate after the intervention. Whereas after intervention respiratory rate there was a statistically significant difference between LIIT and control group of students with, $\mathrm{t}(38)=-4.643$, $\mathrm{p}$-value $<0.000$. The recovery rate for LIIT and control group after exercising was statistically significant with, t $(38)=-6.286$, p-value $<0.000$. Breath-hold for LIIT

\begin{tabular}{|c|c|c|c|c|c|c|c|c|c|}
\hline \multirow{3}{*}{ Variables } & \multirow{3}{*}{$\mathbf{N}$} & \multicolumn{2}{|l|}{ Minimum } & \multicolumn{2}{|l|}{ Maximum } & \multicolumn{2}{|l|}{ Mean } & \multicolumn{2}{|c|}{ Std. Deviation } \\
\hline & & \multicolumn{2}{|c|}{ Experimental Control } & \multicolumn{2}{|c|}{ Experimental Control } & \multicolumn{2}{|c|}{ Experimental Control } & \multicolumn{2}{|c|}{ Experimental Control } \\
\hline & & group & group & group & group & group & group & group & group \\
\hline Age & 20 & 19 & 19 & 25 & 24 & 21.15 & 20.95 & 1.872 & 1.669 \\
\hline Body mass & 20 & 61.00 & 61.60 & 68.00 & 64.00 & 62.9300 & 62.4500 & 1.87311 & .77832 \\
\hline Height & 20 & 1.60 & 1.59 & 1.76 & 1.78 & 1.6800 & 1.6940 & .04542 & .04773 \\
\hline Body mass index & 20 & 20.62 & 20.01 & 26.23 & 24.41 & 22.3375 & 21.8060 & 1.30126 & 1.15423 \\
\hline
\end{tabular}

Table 1. Participants demographic characteristics 
Table 2. The mean value between low-intensity interval training and control group within 8 weeks of follow-up.

\begin{tabular}{llllll}
\hline Group Statistics & & & & & \\
\hline Variables & Group & N & Mean & Std. Deviation & Std. Error Mean \\
\hline \multirow{2}{*}{ Resting heart rate } & Low & 20 & 63.00 & 6.882 & 1.539 \\
& control & 20 & 74.10 & 7.093 & 1.586 \\
Respiratory rate & Low & 20 & 17.65 & 3.014 & .674 \\
& control & 20 & 21.90 & 2.770 & .619 \\
Recovery rate & Low & 20 & 17.70 & 9.229 & 2.064 \\
& control & 20 & 38.50 & 11.569 & 2.587 \\
Breath hold & Low & 20 & 45.4145 & 16.24769 & 3.63309 \\
Vo2max & control & 20 & 33.1335 & 14.35613 & 3.21013 \\
Systolic blood pressure & Low & 20 & 47.4400 & 6.78393 & 1.51693 \\
& control & 20 & 39.6350 & 9.05139 & 2.02395 \\
Diastolic blood pressure & Low & 20 & 114.00 & 8.208 & 1.835 \\
& control & 20 & 120.50 & 8.870 & 1.983 \\
\hline
\end{tabular}

Table 3. Changes in outcome between the intervention group doing Low-intensity interval training and the control group within 8 weeks of follow-up.

Independent Samples T Test of Male students' physiological variable test with Experimental and control group

\begin{tabular}{|c|c|c|c|c|c|c|}
\hline \multirow{2}{*}{ Variables } & \multicolumn{3}{|c|}{ Levene's Test for Equality of Variances } & \multicolumn{3}{|c|}{ t-test for Equality of Means } \\
\hline & Md. & $\mathbf{F}$ & Sig. & $\mathbf{T}$ & Df & Sig.(2t) \\
\hline Resting heart rate & -11.10 & 0.007 & 0.934 & -5.020 & 38 & 0.001 \\
\hline Respiratory rate & -4.25 & 0.049 & 0.827 & -4.643 & 38 & 0.001 \\
\hline Recovery rate & -20.80 & 4.124 & 0.075 & -6.286 & 38 & 0.001 \\
\hline Breath hold & 12.281 & 0.330 & 0.569 & 2.533 & 38 & 0.016 \\
\hline Vo2max & 7.805 & 0.556 & 0.460 & 3.086 & 38 & 0.004 \\
\hline SBP & -6.500 & 0.383 & 0.540 & -2.405 & 38 & 0.021 \\
\hline DBP & -8.500 & 0.569 & 0.455 & -3.521 & 38 & 0.001 \\
\hline
\end{tabular}

$\mathrm{t}$-Test, df- degree of freedom, sig- significant, MD- mean difference

and control group after the intervention was statistically significant with, t $(38)=2.533$, p-value $<0.016$. This indicates that the low-intensity exercises group were lower respiratory, recovery rate, breath-hold than the control group. $\mathrm{Vo}_{2} \max$ after the intervention was again statistically significant with, $\mathrm{t}(38)=3.086$, p-value $<$ 0.004 . This also indicates that students who exercise lowintensity training were higher $\mathrm{Vo}_{2} \max$ than the control group. After the experiment for LIIT and control group Systolic blood pressure was statistically significant with, $\mathrm{t}(38)=-2.405$, p-value $<0.021$. Diastolic blood pressure for LIIT and control group after exercising it was statistically highly significant with, $\mathrm{t}(38)=0.569$, p-value $<0.001$. This implies that low-intensity the exercising group had lower SBP and DBP than the control group.

\section{Discussions}

The purpose of this study was to evaluate the effects of LIIT on physiological variables of university students. The results of the present study show that there was a significant difference in resting heart rate, respiratory rate, recovery heart rate, breath-hold, vo2-max, and systolic and diastolic blood pressure between LIIT and the control group.

The decrease in resting heart rate subsequent to endurance training may be attributed to a decrease in intrinsic rate augmented blood volume, enhance left ventricular ejection fraction, an increase in cardiac parasympathetic efferent activity, and a decrease in cardiac sympathetic efferent activity [38]. In agreement with previous reports the RHR significantly decreased more in the exercising group compared to the control group (all 
studies: $-4.7 \%$ and -3.3 bpm resp., females only: $-4.8 \%$ and $-3.4 \mathrm{bpm}$, resp., males only: $-6.4 \%$ and $-4.3 \mathrm{bpm}$, resp., studies including both females and males: $-3.6 \%$ and -2.6 bpm, resp.) [11].

Previous studies on resting heart rate reported that LIIT changes, resting heart rate [32]. This change may occur due to the effect of the training improved cardiovascular and performance capacity related to an increased stroke volume and cardiac output. The mechanisms also enhanced diastolic filling parameters at the highest heart rates associated with maximal exercise. There is also a component of peripheral blood flow adjustment to training that contributes to the enhanced exercise capacity posttraining. A modest increase in the ability to extract oxygen as assessed by arteriovenous oxygen difference. These findings are similar to the current study. This is likely due to changes in the ability to preferentially re-route blood flow to active muscle tissues, a greater capillarization of active skeletal muscle beds, and the enhanced oxygen extraction capability of the trained muscle cells with greater numbers of mitochondria and oxidative enzymes. Therefore, increasing the efficiency of heart rate muscles, ventricular cavity size, and stroke volume, or neural adaptation to decrease sympathetic tone to the sinoatrial node and increase parasympathetic tone which plays a role in reducing the resting heart rate [32].

Similarly, this study illustrated a significant difference in respiratory rate between LIIT groups and the control groups following the eight-week intervention. This finding is in agreement with Low-intensity interval training may constitute an effective training protocol for improving VO2 max and cardiovascular endurance [39].

Previous studies indicate that Low-intensity interval training has positive improvement in respiratory rate [40-42]. This may be due to the effect of the training on improving ventilation pre-and post-training, at rest, and during low-intensity exercise and changes in tidal volume, respiratory rate, and ventilator volume of maximal aerobic exercise. Maximal respiratory rate and maximal tidal volume increase post-training for a profound effect upon maximal ventilator volume [43-45].

Based on different study findings, the effect of high-intensity interval training on recovery heart rate shows better efficiency on students' physiology. Longer recovery intervals resulted in a lower average heart rate and Maximum oxygen uptake over the training session [46-50].

In Sprint interval training protocols, similar beneficial performance outcomes were reported across a multitude of exercise modalities when recovery duration was increased between work intervals [51-54]. The main metabolic processes that take place during recovery from intense exercise, bouts are the repletion of phosphocreatine stores, the removal of hydrogen ions, and restitution of the acidbase balance of the exercising muscles. These processes proceed at different rates, with phosphocreatine having a much faster half- life ( $\sim 30 \mathrm{~s})$ and achieving complete restoration $(\sim 3 \mathrm{~min})$, compared with blood lactate [BLa] and $\mathrm{pH}$ recovery $(6-10 \mathrm{~min})$ [55-57].
Thus, heart rate recovery contributed positively to the results for two reasons. First, the short recovery time would have meant that the anaerobic energy production systems would not have had sufficient time to fully recover. With each subsequent repetition, the aerobic system would have been required to make a greater contribution to energy production. If enough repetitions of this form of exercise are performed, energy production from the aerobic metabolism will be challenged regularly enough for a training effect to occur. Second, passive recovery has been found to be a more effective strategy when performing supramaximal high-intensity interval training.

For both participants, it was possible to maintain exercise intensity and perform larger workloads per effort using a passive rather than an active recovery strategy. Due to the high energy demands of supramaximal interval training, the oxygen demand for each subsequent interval is too high for oxygen to be consumed at all during the shorter recovery period. It can be postulated that the recovery strategy used in the current study contributed to the improvement in aerobic performance because, in theory, more oxygen was available to the subjects to maintain the required intensity. The shorter recovery time would have progressively required a significant contribution from the aerobic system to meet the energy demand $[57,58]$.

After the breath-holding test, the research data showed that high breath-holding capacity and significant improvement were observed in the LIIT group compared to the control group. This could be due to the improvement of respiratory muscle efficiency, which increases tidal volume and increases the number, size and metabolic capacity of mitochondria to increase the oxygen consumption of cells accordingly [44, 59].

The current literature has shown that a regular practice of yoga/breathing exercises can be useful in improving ventilator function. However, a short practice of deep breathing exercises can improve breath holding time [60]. The information described in the literature indicates that intermittent breath holding during moderateintensity exercise provokes consistent changes in muscle oxygenation, leading to lower tissue oxygenation. The data also indicate that exercise with intermittent breath holding induces higher blood lactate concentration [61].

Much of the available literature demonstrates that better improvement in VO2 max was seen in the LIIT group when compared with the control group. This may be due to the intensity exercises enhances the activity of the cardiovascular system as well as the developed oxidative capacity of the skeletal muscles which leads to an increase in the delivery of oxygen to the working muscles. The above result was also confined to the study of [62-65].

The effect of the training on the vascularity of blood vessels or decreasing stiffness of arteries. The decreased resting blood pressure makes it easier for the left ventricle to pump blood because it must develop less force to eject blood into the peripheral circulation. A reduction in both systolic and diastolic blood pressure 
(BP) may be due to the reduced sympathetic nervous activity as well as an increased nitric oxide-mediated vasodilation from exercise. It has been postulated that the mechanism involved in lowering blood pressure from undertaking aerobic exercise specifically, maybe be due to the hormone's norepinephrine and epinephrine, as regular exercise has been shown to reduce the level of norepinephrine, limiting vasoconstriction of the arteriole enabling reduced blood pressure. Furthermore, this reduction in the sympathetic neural activity that may help to reduce the blood pressure from undertaking aerobic exercise [47, 66-70]

Evidence supports the idea that physiological performance can be improved when individuals include LIIT in their training plan $[39,71]$.

The present study recommended that physical education teachers, fitness instructors, and coaches should incorporate a variety of low-intensity interval training methods to improve the performance of their trainees. Similar studies can be conducted involving female students by including other variables for better performance enhancement in selected physiological variables.

\section{Conclusions}

In conclusion, the study results show that eight weeks of low intensity interval training showed a positive effect on physiological variables, namely: resting heart rate, respiratory rate, breathe hold, vo2 max, diastolic and systolic blood pressure compared to the control group.

\section{Conflict of interest}

The author declare that there is no conflict of interest regarding the publication of this article.

\section{References}

1. Gibala MJ, Gillen JB, Percival ME. Physiological and HealthRelated Adaptations to Low-Volume Interval Training. Influences of Nutrition and Sex. Sports Med, 2014;44:127-37. https://doi.org/10.1007/s40279-014-0259-6

2. Belardinelli R, Georgiou D, Scocco V, Barstow TJ, Purcaro A. Low intensity exercise training in patients with chronic heart failure. Journal of the American College of Cardiology, 1995;26:975-82. https://doi.org/10.1016/0735-1097(95)00267-1

3. Gaesser GA, Rich RG. Effects of high- and low-intensity exercise training on aerobic capacity and blood lipids. Med Sci Sport Exerc. 1984;16:269-74.

4. Lazzer S, Tringali G, Caccavale M, De Micheli R, Abbruzzese L, Sartorio A. Effects of high-intensity interval training on physical capacities and substrate oxidation rate in obese adolescents. $J$ Endocrinol Invest, 2017;40:217-26. https://doi.org/10.1007/s40618-016-0551-4

5. Mang ZA, Fennel ZJ, Realzola RA, Wells AD, McKenna $\mathrm{Z}$, Droemer $\mathrm{C}$, et al. Heat acclimation during lowintensity exercise increases and Hsp72, but not markers of mitochondrial biogenesis and oxidative phosphorylation, in skeletal tissue. Exp Physiol 2021;106:290-301. https://doi.org/10.1113/EP088563

6. Takada S, Okita K, Suga T, Omokawa M, Kadoguchi $\mathrm{T}$, Sato $\mathrm{T}$, et al. Low-intensity exercise can increase muscle mass and strength proportionally to enhanced metabolic stress under ischemic conditions. Journal of Applied Physiology, 2012;113:199-205. https://doi.org/10.1152/japplphysiol.00149.2012

7. Weston M, Taylor KL, Batterham AM, Hopkins WG. Effects of Low-Volume High-Intensity Interval Training (HIT) on Fitness in Adults: A Meta-Analysis of Controlled and Non-Controlled Trials. Sports Med, 2014;44:1005-17. https://doi.org/10.1007/s40279-014-0180-z

8. Emter CA, Tharp DL, Ivey JR, Ganjam VK, Bowles DK. Low-intensity interval exercise training attenuates coronary vascular dysfunction and preserves $\mathrm{Ca}{ }^{2+}$ -sensitive $\mathrm{K}{ }^{+}$current in miniature swine with LV hypertrophy. American Journal of Physiology-Heart and Circulatory Physiology, 2011;301:H1687-94. https://doi.org/10.1152/ajpheart.00610.2011

9. Emter CA, Baines CP. Low-intensity aerobic interval training attenuates pathological left ventricular remodeling and mitochondrial dysfunction in aortic- banded miniature swine. American Journal of PhysiologyHeart and Circulatory Physiology, 2010;299:H1348-56. https://doi.org/10.1152/ajpheart.00578.2010

10.Marshall KD, Muller BN, Krenz M, Hanft LM, McDonald $\mathrm{KS}$, Dellsperger $\mathrm{KC}$, et al. Heart failure with preserved ejection fraction: chronic low-intensity interval exercise training preserves myocardial $\mathrm{O}_{2}$ balance and diastolic function. Journal of Applied Physiology, 2013;114:131-47. https://doi.org/10.1152/japplphysiol.01059.2012

11.Reimers A, Knapp G, Reimers C-D. Effects of Exercise on the Resting Heart Rate: A Systematic Review and MetaAnalysis of Interventional Studies. J Clin Med., 2018;7:503. https://doi.org/10.3390/jcm7120503

12.Silva DAS, Lima TR de, Tremblay MS. Association between Resting Heart Rate and Health-Related Physical Fitness in Brazilian Adolescents. BioMed Research International, 2018;2018:1-10. https://doi.org/10.1155/2018/3812197

13.Chicco AJ, Hydock DS, Schneider CM, Hayward R. Low-intensity exercise training during doxorubicin treatment protects against cardiotoxicity. Journal of Applied Physiology, 2006;100:519-27. https://doi.org/10.1152/japplphysiol.00148.2005

14.Van Den Berg R, DeGrootS, SwartKMA, VanDerWoudeLHV. Physical capacity after 7 weeks of low-intensity wheelchair training. Disability and Rehabilitation, 2010;32:1717-21. https://doi.org/10.3109/09638281003649961

15.Gillen JB, Percival ME, Ludzki A, Tarnopolsky MA, Gibala MartinJ. Interval training in the fed or fasted state improves body composition and muscle oxidative capacity in overweight women: Interval Training Improves Body Composition. Obesity, 2013;21:2249-55. https://doi.org/10.1002/oby.20379

16.Hood MS, Little JP, Tarnopolsky MA, Myslik F, Gibala MJ. Low-Volume Interval Training Improves Muscle Oxidative Capacity in Sedentary Adults. Medicine \& Science in Sports \& Exercise, 2011;43:1849-56. https://doi.org/10.1249/MSS.0b013e3182199834

17.Little JP, Gillen JB, Percival ME, Safdar A, Tarnopolsky MA, Punthakee $Z$, et al. Low-volume high-intensity interval training reduces hyperglycemia and increases muscle mitochondrial capacity in patients with type 2 diabetes. Journal of Applied Physiology, 2011;111:1554-60. https://doi.org/10.1152/japplphysiol.00921.2011

18.Babraj JA, Vollaard NB, Keast C, Guppy FM, Cottrell 
G, Timmons JA. Extremely short duration high intensity interval training substantially improves insulin action in young healthy males. BMC Endocr Disord, 2009;9:3. https://doi.org/10.1186/1472-6823-9-3

19.Jakeman J, Adamson S, Babraj J. Extremely short duration high-intensity training substantially improves endurance performance in triathletes. Appl Physiol Nutr Metab, 2012;37:976-81. https://doi.org/10.1139/h2012-083

20.TjønnaAE, Stølen TO, ByeA, Volden M, Slørdah1 SA, Ødegård $\mathrm{R}$, et al. Aerobic interval training reduces cardiovascular risk factors more than a multitreatment approach in overweight adolescents. Clinical Science, 2009;116:317-26. https://doi.org/10.1042/CS20080249

21.Chicco AJ, McCune SA, Emter CA, Sparagna GC, Rees ML, Bolden DA, et al. Low-Intensity Exercise Training Delays Heart Failure and Improves Survival in Female Hypertensive Heart Failure Rats. Hypertension, 2008;51:1096-102. https://doi.org/10.1161/HYPERTENSIONAHA.107.107078

22.Otsuki T, Kotato T, Zempo-Miyaki A. Habitual exercise decreases systolic blood pressure during low-intensity resistance exercise in healthy middle-aged and older individuals. American Journal of Physiology-Heart and Circulatory Physiology, 2016;311:H1024-30. https://doi.org/10.1152/ajpheart.00379.2016

23.Janssen I, LeBlanc AG. Systematic review of the health benefits of physical activity and fitness in school-aged children and youth. Int J Behav Nutr Phys Act, 2010;7:40. https://doi.org/10.1186/1479-5868-7-40

24.Sherar LB, Esliger DW, Baxter-Jones ADG, Tremblay MS. Age and Gender Differences in Youth Physical Activity: Does Physical Maturity Matter? Medicine \& Science in Sports \& Exercise, 2007;39:830-5. https://doi.org/10.1249/mss.0b013e3180335c3c

25.Metcalf BS, Voss LD, Hosking J, Jeffery AN, Wilkin TJ. Physical activity at the government-recommended level and obesity-related health outcomes: a longitudinal study (Early Bird 37). Archives of Disease in Childhood, 2008;93:772-7. https://doi.org/10.1136/adc.2007.135012

26.Riddoch CJ, Mattocks C, Deere K, Saunders J, Kirkby J, Tilling K, etal.Objectivemeasurementoflevelsandpatternsofphysical activity. Archives of Disease in Childhood, 2007;92:963-9. https://doi.org/10.1136/adc.2006.112136

27.Fernandez-Fernandez J, Zimek R, Wiewelhove T, Ferrauti A. High-Intensity Interval Training vs. Repeated-Sprint Training in Tennis. Journal of Strength and Conditioning Research, 2012;26:53-62. https://doi.org/10.1519/JSC.0b013e318220b4ff

28.Guetterman TC, Fetters MD, Creswell JW. Integrating Quantitative and Qualitative Results in Health Science Mixed Methods Research Through Joint Displays. The Annals of Family Medicine, 2015;13:554-61. https://doi.org/10.1370/afm.1865

29.Bryman A. Social research method. 5th ed. New York, NY 100016: Oxford University press; 2008.

30.Rabbia F, Grosso T, Cat Genova G, Conterno A, De Vito B, Mulatero $P$, et al. Assessing resting heart rate in adolescents: determinants and correlates. J Hum Hypertens, 2002;16:327-32. https://doi.org/10.1038/sj.jhh.1001398

31.Galka S, Berrell J, Fezai R, Shabella L, Simpson P, Thyer L. Accuracy of student paramedics when measuring adult respiratory rate: a pilot study. Australasian Journal of Paramedicine, 2019;16. https://doi.org/10.33151/ajp.16.566

32.Wheatley I. Respiratory rate 3. Nurs Times, 2018;114:21-2.
33.Skow RJ, Day TA, Fuller JE, Bruce CD, Steinback CD. The ins and outs of breath holding: simple demonstrations of complex respiratory physiology. Advances in Physiology Education, 2015;39:223-31. https://doi.org/10.1152/advan.00030.2015

34.Bandyopadhyay A. Validity of Cooper's 12-minute run test for estimation of maximum oxygen uptake in male university students. Biol Sport, 2014;32:59-63. https://doi.org/10.5604/20831862.1127283

35.Cooper KH. A Means of Assessing Maximal Oxygen Intake: Correlation Between Field and Treadmill Testing. JAMA, 1968;203:201. https://doi.org/10.1001/jama.1968.03140030033008

36.Kappus RM, Ranadive SM, Yan H, Lane-Cordova AD, Cook MD, Sun P, et al. Sex differences in autonomic function following maximal exercise. Biol Sex Differ, 2015;6:28. https://doi.org/10.1186/s13293-015-0046-6

37.Karavirta L. Electrophysiological adaptations to endurance and strength training. Sex and Cardiac Electrophysiology. Elsevier; 2020, p. 311-21. https://doi.org/10.1016/B978-0-12-817728-0.00027-9

38.Melanson EL, Freedson PS. The effect of endurance training on resting heart rate variability in sedentary adult males. European Journal of Applied Physiology, 2001;85:442-9. https://doi.org/10.1007/s004210100479

39. Batacan RB, Duncan MJ, Dalbo VJ, Tucker PS, Fenning AS. Effects of high-intensity interval training on cardiometabolic health: a systematic review and meta-analysis of intervention studies. Br J Sports Med, 2017;51:494-503. https://doi.org/10.1136/bjsports-2015-095841

40.Arboleda-Serna VH, Feito Y, Patiño-Villada FA, Vargas-Romero AV, Arango-Vélez EF. Effects of highintensity interval training compared to moderateintensity continuous training on maximal oxygen consumption and blood pressure in healthy men: A randomized controlled trial. Biomedica, 2019;39:524-36. https://doi.org/10.7705/biomedica.4451

41.DunhamC,HarmsCA.Effectsofhigh-intensityintervaltraining on pulmonary function. Eur J Appl Physiol, 2012;112:3061-8. https://doi.org/10.1007/s00421-011-2285-5

42.Larsen S, Danielsen JH, Søndergård SD, Søgaard D, Vigelsoe A, Dybboe R, et al. The effect of high-intensity training on mitochondrial fat oxidation in skeletal muscle and subcutaneous adipose tissue: Mitochondria, highintensity training. Scand J Med Sci Sports, 2015;25:e59-69. https://doi.org/10.1111/sms.12252

43.Chlif M, Chaouachi A, Ahmaidi S. Effect of Aerobic Exercise Training on Ventilatory Efficiency and Respiratory Drive in Obese Subjects. Respir Care, 2017;62:936-46. https://doi.org/10.4187/respcare.04923

44.Karen Birch, Keith George, Don McLaren. BIOS Instant Notes in Sport and Exercise Physiology [Internet]. 1st ed. London: Routledge; 2004. Available from: https://www. taylorfrancis.com/books/9780203488249

45.Prado DML, Rocco EA, Silva AG, Rocco DF, Pacheco MT, Silva PF, et al. Effects of continuous vs interval exercise training on oxygen uptake efficiency slope in patients with coronary artery disease. Braz J Med Biol Res, 2016;49. https://doi.org/10.1590/1414-431X20154890

46.Al-Fehaid A, Alkahtani S, Al-Sunni A, Yar T. Role of the work-to-rest ratio in high-intensity interval exercise on heart rate variability and blood pressure in sedentary obese men. Saudi J Health Sci, 2018;7:83. https://doi.org/10.4103/sjhs.sjhs_103_17

47.Alansare A, Alford K, Lee S, Church T, Jung H. The Effects of High-Intensity Interval Training vs. Moderate-Intensity 
Continuous Training on Heart Rate Variability in Physically InactiveAdults. IntJEnviron Res Public Health, 2018;15:1508. https://doi.org/10.3390/ijerph15071508

48.Hyka A, Bicoku E, Mysliu A, Cuka A. The association of sprint performance with anthropometric parameters in youth soccer players. Sport Mont. 2017;15(1): 31-33.

49. Ohya T, Aramaki Y, Kitagawa K. Effect of Duration of Active or Passive Recovery on Performance and Muscle Oxygenation during Intermittent Sprint Cycling Exercise. Int J Sports Med, 2013;34:616-22. https://doi.org/10.1055/s-0032-1331717

50.N I, S R. Low -intensity interval training in a patient with end stage lung disease originally deemed too frail for lung transplant listing. Cardiopulm Phys Ther J, 2018;29:30.

51.Hazell TJ, MacPherson REK, Gravelle BMR, Lemon PWR. 10 or 30-s sprint interval training bouts enhance both aerobic and anaerobic performance. Eur J Appl Physiol, 2010;110:153-60. https://doi.org/10.1007/s00421-010-1474-y

52.Kavaliauskas M, Aspe RR, Babraj J. High-Intensity Cycling Training: The Effect of Work-to-Rest Intervals on Running Performance Measures. Journal of Strength and Conditioning Research, 2015;29:2229-36. https://doi.org/10.1519/JSC.0000000000000868

53.McEwan G, Arthur R, Phillips SM, Gibson NV, Easton C. Interval running with self-selected recovery: Physiology, performance, and perception. European Journal of Sport Science, 2018;18:1058-67. https://doi.org/10.1080/17461391.2018.1472811

54.Toubekis AG, Douda HT, Tokmakidis SP. Influence of different rest intervals during active or passive recovery on repeated sprint swimming performance. Eur J Appl Physiol, 2005;93:694-700. https://doi.org/10.1007/s00421-004-1244-9

55.Buchheit M, Laursen PB. High-Intensity Interval Training, Solutions to the Programming Puzzle: Part I: Cardiopulmonary Emphasis. Sports Med, 2013;43:313-38. https://doi.org/10.1007/s40279-013-0029-x

56.McMahon S, Jenkins D. Factors Affecting the Rate of Phosphocreatine Resynthesis Following Intense Exercise. Sports Medicine, 2002;32:761-84. https://doi.org/10.2165/00007256-200232120-00002

57.Menzies P, Menzies C, McIntyre L, Paterson P, Wilson J, Kemi OJ. Blood lactate clearance during active recovery after an intense running bout depends on the intensity of the active recovery. Journal of Sports Sciences, 2010;28:975-82. https://doi.org/10.1080/02640414.2010.481721

58.Rey E, Lago-Peñas C, Casáis L, Lago-Ballesteros J. The Effect of Immediate Post-Training Active and Passive Recovery Interventions on Anaerobic Performance and Lower Limb Flexibility in Professional Soccer Players. Journal of Human Kinetics, 2012;31:121-9. https://doi.org/10.2478/v10078-012-0013-9

59.Tomlin DL, Wenger HA. The Relationship Between Aerobic Fitness and Recovery from High Intensity Intermittent Exercise: Sports Medicine, 2001;31:1-11. https://doi.org/10.2165/00007256-200131010-00001
60.Karlsen T, Nes BM, Tjønna AE, Engstrøm M, Støylen A, Steinshamn S. High-intensity interval training improves obstructive sleep apnoea. BMJ Open Sport Exerc Med, 2017;2:bmjsem-2016-000155. https://doi.org/10.1136/bmjsem-2016-000155

61.Associate Professor Department Of Physiology RIMS Ranchi., Kumar Sinha R, a G, Jr Resident, Department Of Physiology, RIMS Ranchi. Impact of short term breathing exercise on breath holding time. Int J Adv Res, 2020;8:960-3. https://doi.org/10.21474/IJAR01/11574

62.Duffield R, Edge J, Bishop D. Effects of high-intensity interval training on the response during severe exercise. Journal of Science and Medicine in Sport, 2006;9:249-55. https://doi.org/10.1016/j.jsams.2006.03.014

63.Kume D, Akahoshi S, Song J, Yamagata T, Wakimoto T, Nagao M, et al. Intermittent breath holding during moderate bicycle exercise provokes consistent changes in muscle oxygenation and greater blood lactate response. $J$ Sport Med Phys Fit. 2013;53:327-35.

64.Reilly T. An ergonomics model of the soccer training process. Journal of Sports Sciences, 2005;23:561-72. https://doi.org/10.1080/02640410400021245

65.Tabata I, Nishimura K, Kouzaki M, Hirai Y, Ogita F, Miyachi $M$, et al. Effects of moderate-intensity endurance and high-intensity intermittent training on anaerobic capacity and??VO2max. Medicine \&amp Science in Sports \&amp Exercise, 1996;28:1327-30. https://doi.org/10.1097/00005768-199610000-00018

66.Fagard RH. Exercise characteristics and the blood pressure response to dynamic physical training. Medicine and Science in Sports and Exercise, 2001;33:S484-92. https://doi.org/10.1097/00005768-200106001-00018

67.Gossard D, Haskell WL, Taylor CB, Mueller JK, Rogers F, ChandlerM, etal.Effectsoflow-andhigh-intensityhome-based exercise training on functional capacity in healthy middle-aged men. The American Journal of Cardiology, 1986;57:446-9. https://doi.org/10.1016/0002-9149(86)90770-8

68.Hardcastle SJ, Ray H, Beale L, Hagger MS. Why sprint interval training is inappropriate for a largely sedentary population. Front Psychol, 2014;5. https://doi.org/10.3389/fpsyg.2014.01505

69. Rice T, Rankinen T, Province MA, Chagnon YC, Pérusse L, Borecki IB, et al. Genome-Wide Linkage Analysis of Systolic and Diastolic Blood Pressure: The Québec Family Study. Circulation, 2000;102:1956-63. https://doi.org/10.1161/01.CIR.102.16.1956

70.Trilk JL, Singhal A, Bigelman KA, Cureton KJ. Effect of sprint interval training on circulatory function during exercise in sedentary, overweight/ obese women. Eur J Appl Physiol, 2011;111:1591-7. https://doi.org/10.1007/s00421-010-1777-z

71.Wisløff U, Ellingsen Ø, Kemi OJ. High-Intensity Interval Training to Maximize Cardiac Benefits of Exercise Training? Exercise and Sport Sciences Reviews, 2009;37:139-46. https://doi.org/10.1097/JES.0b013e3181aa65fc 


\section{Information about the author:}

Assegid Ketema; Lecturer; https://orcid.org/0000-0003-1494-0071; assegidketema61@gmail.com; Sport Science Department, Collage of Natural Science, Arba Minch University, Ethiopia.

Cite this article as:

Ketema A. Effects of low intensity interval training on physiological variables of university students. Pedagogy of Physical Culture and Sports, 2021;25(5):333-341.

https://doi.org/10.15561/26649837.2021.0508

This is an Open Access article distributed under the terms of the Creative Commons Attribution License, which permits unrestricted use, distribution, and reproduction in any medium, provided the original work is properly cited (http://creativecommons.org/licenses/by/4.0/deed.en).

Received: 20.07.2021

Accepted: 27.08.2021; Published: 30.10.2021 